\title{
Prophylactic Danshen Injection Combined with Prostaglandin E1 and Low-dose Heparin may prevent Hepatic Veno-occlusive Disease after Hematopoietic Stem Cell Transplantation: A Single-center Study in China
}

\author{
Xiaoning Wang, Chunhong Sun, Caili Guo, Pengcheng He*and Mei Zhang* \\ Department of Hematology, The First Affiliated Hospital of Xi'an Jiaotong University, Xi'an, ShaanXi, P. R. China
}

"Corresponding authors: Mei Zhang, Department of Hematology, The First Affiliated Hospital of Xi'an Jiaotong University, Xi'an, ShaanXi-710061, P. R. China, Tel: +86-18991232609; Fax: +86-029-85324085; E-mail: zhangmeimedmail@163.com

Pengcheng He, Department of Hematology, The First Affiliated Hospital of Xi'an Jiaotong University, Xi'an, ShaanXi-710061, P. R. China, Tel: +86-18991232153; Fax: +86-029-85324085; E-mail: hepc@163.com

Received date: March 31, 2017; Accepted date: April 18, 2017; Published date: April 20, 2017

Copyright: $\odot 2017$ Wang X, et al. This is an open-access article distributed under the terms of the Creative Commons Attribution License, which permits unrestricted use, distribution, and reproduction in any medium, provided the original author and source are credited.

\begin{abstract}
Objective: To investigate the effect of Danshen injection combined with prostaglandin E1 and low-dose heparinon prevention of hepatic veno-occlusive disease (HVOD) after hematopoietic stem cell transplantation (HSCT). Methods: A total of 126 patients undergoing HSCT between January 2008 and June 2015, received a combined prophylactic regimen of intravenous Danshen 20-30 ml/day, prostaglandin E 120-30 $\mu \mathrm{g} / \mathrm{d}$, and subcutaneous injection of low-dose heparin (100 U/kg/day) for prevention of HVOD. The incidence of HVOD and adverse events associated with this prophylactic regimen were observed.
\end{abstract}

Results: Among 126 patients, 65 received autologous peripheral blood stem cell transplant, 34 received HLAidentical sibling HSCT, six received HLA mismatched siblingHSCT, seven received HLA-matched unrelated HSCT, and 14 received HLA-mismatched unrelated HSCT. No adverse reaction or coagulation disorder associated with this prophylactic regimen was observed. Only one case with acute myeloid leukemia (CR2) developed HVOD seven days after receiving myeloablative chemotherapy with oral busulfan and cyclophosphamide followed by HLAmismatched unrelated peripheral blood stem cell transplantation. This patient died of HVOD.

Conclusion: Danshen injection combined with prostaglandin E1 and low-dose heparin is a safe and effective regimen for the prevention of HVOD after HSCT.

Keywords: Danshen injection; Prostaglandin E1; Low-dose heparin; Hepatic veno-occlusive disease; Hematopoietic stem cell transplantation

\section{Introduction}

Veno-occlusive disease (VOD) of the liver is a severe complication of hematopoietic stem cell transplantation (HSCT). The incidence of VOD is reported to range from $5 \%$ to $60 \%$ in adults and from $18 \%$ to $28 \%$ in children [1]. The risk factors for VOD include older age, advanced disease, conditioning regimen especially oral Busulfan regimen, HLA mismatched, unrelated donors, non-T-cell depleted graft and positive serology results for Cytomegalovirus (CMV), Hepatitis B virus (HBV), or Hepatitis C virus (HCV) [2,3]. The mortality rate of VOD is nearly $50 \%$ [4]. Currently, there is no standard prophylactic regimen for this serious complication. Many studies have shown that low-dose heparin, prostaglandin E1, antithrombin, ursodeoxycholic acid, and defibrotide, alone or combination, were effective in preventing VOD. However, the incidence of VOD is still high and the effects of these drugs are controversial [5-7]. Recently, it has been reported that neither prophylactic low-dose heparin nor lipo-prostaglandin E1 reduced the incidence of VOD, although these prophylactic strategies did reduce the severity of VOD [8].
Danshen injection, a Traditional Chinese Medicine formulation, has been widely used in the treatment of coronary heart diseases, myocardial infarction, and hypertension. Danshen is a crude herbal drug isolated from the dried root of Salvia miltiorrhiza Bunge (Lamiaceae). This plant is widely used in Asia, United States of America, and the European countries for the treatment of coronary heart disease, menstrual disorders, menostasis, blood circulation diseases, and other cardiovascular diseases [9]. Danshen activates blood circulation and dissipates blood stasis [10]. Its beneficial effects are attributable to its microcirculation-improving, vasodilatory, anticoagulant, anti-thrombotic, anti-inflammatory, free radical scavenging, and mitochondria-protective activities. Moreover, it has showed beneficial effects as an anti-dementia, antioxidant, and antitumor agent. Some reports show that Danshen injections have inhibitory effects on platelet aggregation and prothrombolytic activity [11]. Pharmacological studies have shown that water-soluble extracts from Danshen can provide an alternative regimen for the prevention of ischemic heart disease [12-15]. Danshen has also been demonstrated to be having protective effects on liver injury models induced by carbon tetrachloride, D-galactosamine, acetaminophen, and alcohol [16].

The chemical constituents of $S$. miltiorrhiza have been studied for more than 60 years, but research has been focused mainly on the lipophilic diterpenoid quinones. In recent decades, the pharmacological activities of the water-soluble components of $S$. 
Citation: Zhang M, Wang X, Sun C, Guo C, He P (2017) Prophylactic Danshen Injection Combined with Prostaglandin E1 and Low-dose Heparin may prevent Hepatic Veno-occlusive Disease after Hematopoietic Stem Cell Transplantation: A Single-center Study in China. J Blood Disord Transfus 8: 378. doi:10.4172/2155-9864.1000378

Page 2 of 4

miltiorrhiza have been investigated, including the active constituents magnesium lithospermate B (MLB, also called salvianolic acid B), rosmarinic acid (RA), lithospermic acid (LA), prolithospermic acid, ammonium potassium lithospermate $\mathrm{B}$, and magnesium salvianolate $\mathrm{E}$ oligomers of caffeic acids [17,18].

The purpose of this study was to investigate the effects of a combination therapy consisting of prophylactic low-dose heparin, prostaglandin E1, and Danshen injections on VOD prevention in patients undergoing HSCT.

\section{Materials and Methods}

\section{Patients}

One hundred and twenty-six patients underwent HSCT at the Department of Hematology, the First Affiliated Hospital of Xian Jiaotong University, between January 2008 and June 2015. All procedure were in accordance with the ethical standards of the institutional and/or national research committee and the 1964 Declaration of Helsinki. All patients provided written informed consent for participation in the study.

\section{Prophylactic treatment for VOD}

Prophylactic low-dose heparin (Heparinsodium, Shanghai No.1 Biochemical \& Pharmaceutical Co. LTD, Shanghai, China) was injected subcutaneously at a dose of $100 \mathrm{U} / \mathrm{kg} /$ day. Prostaglandin E1 (Alprostadilinjection, Beijing Tide Pharmaceutical Co. LTD, Beijing, China) was injected intravenously at a dose of $10 \mu \mathrm{g}$ per 8 hour in adults or 12 hour in children. Intravenous Danshen injections (Chiatai Qingchunbao Pharmaceutical Co. LTD, Shanghai, China) were provided at a dose of $30 \mathrm{ml} /$ day in adults and $20 \mathrm{ml} /$ day in children. The drugs for the prevention of VOD were administered starting on preoperative day 7 until postoperative day 30 . When platelet count was $<70 \times 10^{9} / \mathrm{L}$, heparin and Danshen injections were discontinued. When the platelet count was $<20 \times 10^{9} / \mathrm{L}$ prostaglandin $\mathrm{E} 1$ injections were discontinued. Additionally, heparin was discontinued if the activated partial thromboplastin time (APTT) was found to be $\geq 1.2$ fold compared to the normal or if there were any major bleeding episodes.

\section{VOD definition}

A diagnosis of VOD required two of the following within 20 days of transplantation according to the Seattle clinical criteria: Serumbilirubin $>2 \mathrm{mg} / \mathrm{dl}$, hepatomegaly, and weight gain $>2 \%$ over baseline [19].

\section{Results}

\section{Patient characteristics}

The characteristics of the study sample at the time of transplantation are shown in (Table 1). The median age at the time of HSCT was 38 years (range: 4-63 years), and 16 patients were children. Of the 126 patients, 66 patients were diagnosed with acute leukemia, 9 with chronic myelogenous leukemia, 39 with lymphoma and 12 with plasma disease. Sixty-five patients received autologous hematopoietic stem cell transplantation while 61 received an allogeneic transplantation. Ten patients had HBV infection and one had HCV infection before transplantation. None of the patients had abnormal liver function prior to the start of conditioning. Preparative conditioning was mostly ablative, including total body irradiation (TBI) (2) and chemotherapybased regimens (124). Graft-versus-host disease (GVHD) prophylaxis included short-duration methotrexate (MTX), cyclosporine A (CsA), and mycophenolate mofetil (MMF) regimens in allo-HSCT patients.

\begin{tabular}{|c|c|c|}
\hline Age (years) & $<18$ & $\geq 18$ \\
\hline Number & 16 & 110 \\
\hline \multicolumn{3}{|l|}{ Gender } \\
\hline Males & 12 & 74 \\
\hline Females & 4 & 36 \\
\hline \multicolumn{3}{|l|}{ Primary diagnosis } \\
\hline AML ( $\left.1^{\text {st }} \mathrm{CR}\right)$ & 6 & 33 \\
\hline $\operatorname{AML}\left(\geq 2^{\text {nd }} C R\right)$ & 1 & 3 \\
\hline ALL $\left(1^{\text {st }} \mathrm{CR}\right)$ & 0 & 18 \\
\hline $\operatorname{ALL}\left(\geq 2^{\text {nd }} C R\right)$ & 2 & 1 \\
\hline Acute mixed leukemia & 0 & 2 \\
\hline \multicolumn{3}{|l|}{ CML } \\
\hline $\mathrm{CP}$ & 4 & 3 \\
\hline AP & 0 & 1 \\
\hline BP & 0 & 1 \\
\hline $\mathrm{NHL}$ & 3 & 33 \\
\hline $\mathrm{HL}$ & 0 & 3 \\
\hline MM & 0 & 10 \\
\hline Extra medullary plasmacytoma & 0 & 2 \\
\hline \multicolumn{3}{|l|}{ Stem cell source } \\
\hline BM & 0 & 1 \\
\hline PB & 16 & 109 \\
\hline \multicolumn{3}{|l|}{ Donor type and HLA-match } \\
\hline \multicolumn{3}{|l|}{ Allogeneic, related } \\
\hline HLAmatch & 4 & 30 \\
\hline $1 \mathrm{Ag}$ mismatch & 0 & 1 \\
\hline $2 \mathrm{Ag}$ mismatch & 0 & 1 \\
\hline $3 \mathrm{Ag}$ mismatch & 1 & 4 \\
\hline \multicolumn{3}{|l|}{ Allogeneic, unrelated } \\
\hline HLA match & 1 & 6 \\
\hline $1 \mathrm{Ag}$ mismatch & 2 & 6 \\
\hline $2 \mathrm{Ag}$ mismatch & 0 & 6 \\
\hline Autologous & 6 & 59 \\
\hline Preparative regimen & & \\
\hline
\end{tabular}


Citation: Zhang M, Wang X, Sun C, Guo C, He P (2017) Prophylactic Danshen Injection Combined with Prostaglandin E1 and Low-dose Heparin may prevent Hepatic Veno-occlusive Disease after Hematopoietic Stem Cell Transplantation: A Single-center Study in China. J Blood Disord Transfus 8: 378. doi:10.4172/2155-9864.1000378

Page 3 of 4

\begin{tabular}{|l|l|l|}
\hline Allogeneic & 9 & 50 \\
\hline Bu-based & 0 & 2 \\
\hline TBI-based & 4 & 36 \\
\hline Autologous & 4 & 2 \\
\hline BEAC & 1 & 11 \\
\hline CBV & 7 & 11 \\
\hline Mel-based & 2 & 1 \\
\hline BuCy & 0 & 1 \\
\hline TBI & 0 & \\
\hline Others & & 29 \\
\hline GVHD prophylaxis & 5 & 23 \\
\hline CsA+MTX+MMF & 4 & \\
\hline CsA+MTX+MMF+ATG & & \\
\hline CMV serology positivity pre-transplantation &
\end{tabular}

\section{Allogeneic}

\begin{tabular}{|l|l|l|}
\hline Recipient only & 3 & 15 \\
\hline Donor only & 0 & 4 \\
\hline Recipient and donor & 5 & 34 \\
\hline
\end{tabular}

Autologous recipients

\begin{tabular}{|l|l|l|}
\hline $\mathrm{CMV}+$ & 6 & 42 \\
\hline $\mathrm{CMV}-$ & 2 & 15 \\
\hline
\end{tabular}

HBV serology status, recipient

\begin{tabular}{|l|l|l|}
\hline Positive & 1 & 9 \\
\hline Negative & 15 & 101 \\
\hline
\end{tabular}

HCV serology status, recipient

\begin{tabular}{|l|l|l|}
\hline Positive & 0 & 1 \\
\hline Negative & 16 & 109 \\
\hline
\end{tabular}

Table 1: The characteristics of the study sample at the time of transplantation

\section{Incidence of VOD}

One of 126 patients $(0.79 \%)$ developed VOD. This patient had acute myeloid leukemia, and had experienced a second remission before receiving an unrelated allogeneic stem cell transplant. The conditioning regimen was as follows: busulfan $(4 \mathrm{mg} / \mathrm{kg} /$ day $)$ orally on days -7 to- 4 (i.e. from preoperative day 7 to preoperative day 4 ), intravenous cyclophosphamide $(60 \mathrm{mg} / \mathrm{kg} /$ day) on days -3 to -2 , methyl chloride hexamethylene urea nitrate Me-CCNU; $250 \mathrm{mg} / \mathrm{m}^{2} /$ day) orally once on day-3, and intravenous antithymoglobulin (ATG; $2.5 \mathrm{mg} / \mathrm{kg} /$ day) on days -4 to -2 . On postoperative day 7 , VOD was diagnosed.

\section{Bleeding complications and survival}

The coagulation parameters such as activated partial thromboplastintime (APTT) and prothrombintime (PT) were monitored every week. None of the patients showed $\geq 2$-fold increase in APTT compared to the baseline value. Most patients developed petechia at the injection site. None, however, developed hematoma. None of the patients showed organ bleeding due to VOD prophylaxis.

Thirty-four patients died in all, among which two died within 100 days after the transplant. Of these two died patients, the death of one could be attributed directly to VOD, while the other died of posttransplant lymphoproliferative disorder (PTLD).

\section{Discussion}

VOD is one of the most common complications of HSCT. Danshen, a Traditional Chinese Medicine formulation, has been widely used in the treatment of coronary heart diseases, myocardial infarction, and hypertension. In this study, we tried to investigate the efficacy of Danshen injection in the prevention of VOD.

The risk factors for VOD include transplant-related factors, as well as patient and disease characteristics. VOD is more common after allogeneic HSCT (allo-HSCT) accompanied by amyeloablative conditioning regimen, or with unrelated/HLA-mismatched donors, compared with allo-HSCT with reduced intensity conditioning regimen and autologous HSCT (auto-HSCT) [2]. Busulfan, especially oral busulfan, combination with cyclophosphamideis associated with an increased risk of VOD [3]. Older age, impaired Karnofsky status (< 90) and advanced-stage disease have been reported asrisk factors for VOD. Previous hepatic disease is also one of the main risk factors of VOD [2]. In our study, 61 patients underwent allo-HSCT, including 21 cases of unrelated HSCT and 23 cases of HLA-mismatched allo-HSCT; of these 61 patients, 9 had advanced-stage disease and 11 had a history of hepatic disease. We found that a combination of prophylactic lowdose heparin, prostaglandin E1, and Danshen injection could effectively prevent VOD in patients undergoing HSCT. The incidence of VOD was only $0.79 \%$, which is far lower than the reported incidence among both adults and children. The patients in this study were exposed to most of the risk factors for VOD. In spite of this, only one patient received oral busulfan as conditioning regimen and underwent unrelated HLA-mismatched HSCT; this patient also had previous HBV infection and advanced-stage diseases. Exposure to a range of risk factors finally led to the development of VOD. Based on our analysis, we postulated that VOD was successfully prevented in high-risk HSCT patients.

Drugs used to prevent VOD include heparin, prostaglandin E1, anti-thrombin III, ursodeoxycholic acid, and defibrotide (DF), alone or in combination. Among these, the use of heparin is still very controversial. Some trials showed that unfractionated or lowmolecular-weight heparin decreased the risk for VOD insignificantly; however, some showed a beneficial effect of heparin. Bleeding was reported as an adverse event in most studies [5]. At present, heparin is used for VOD prevention in some European Society for Blood and Marrow Transplantation (EBMT) centers.

Prostaglandin E1 is a vasodilator with inhibitory effects on platelet aggregation and prothrombolytic activity, and can reduce the overall incidence of VOD. It has been reported that prophylactic low-dose heparin or prostaglandin E1, alone or in combination, could not significantly reduce the incidence of VOD, although these prophylactic 
Citation: Zhang M, Wang X, Sun C, Guo C, He P (2017) Prophylactic Danshen Injection Combined with Prostaglandin E1 and Low-dose Heparin may prevent Hepatic Veno-occlusive Disease after Hematopoietic Stem Cell Transplantation: A Single-center Study in China. J Blood Disord Transfus 8: 378. doi:10.4172/2155-9864.1000378

Page 4 of 4

strategies reduced the severity of VOD [1]. We formulated a combined regimen consisting of heparin, prostaglandin $\mathrm{E} 1$, and a traditional Chinese herb Danshen to prevent VOD. Heparin was injected subcutaneously, whereas the other two were administered via intravenous infusion. The results showed that these three drugs can play a synergistic role in the prevention of VOD, and none of the patients showed organ bleeding due to VOD prophylaxis. Most patients just developed petechiae at the injection site; none, however, developed a hematoma.

The incidence of post-transplantation VOD in children is reported to range from $18 \%$ to $28 \%$. Defibrotide (DF) has been used for preventing VOD in children. It was reported that DF could significantly reduce the incidence of VOD in pediatric patients undergoing HSCT [20,21]. However, no randomized prospective study evaluating VOD prevention with DF has so far been reported in adult patients. In this study, there were 16 pediatric patients, and none developed VOD; this may indicate that our novel prophylactic regimen of heparin combined with prostaglandin E1 and Danshen injection is effective in children also, without the risk of any severe adverse events.

In conclusion, we observed that a combination of low-dose heparin, prostaglandin E1, and Danshen injection was effective in preventing VOD in patients undergoing HSCT. However, this study has a few limitations. The sample size was small and this was not a randomized controlled trial. Further randomized controlled trials are needed to identify and investigate the mechanism of the synergistic effects of this prophylactic regimen.

\section{References}

1. Song JS, Seo JJ, Moon HN, Ghim T, Im HJ (2006) Prophylactic low-dose heparinor prostaglandin E1 may prevent severe veno-occlusive disease of the liver after allogeneic hematopoietic stem cell transplantation in Korean children. J Korean Med Sci 21: 897-903.

2. Coppell JA, Richardson PG, Soiffer R, Martin PL, Kernan NA, et al. (2010) Hepatic veno-occlusive disease following stem cell transplantation: Incidence, clinicalcourse, and outcome. Biol Blood MarrowTransplant 16: 157-168.

3. Nagler A, Labopin M, Berger R, Bunjes D, Campos A, et al.(2014) Allogeneic hematopoietic SCT for adults AML using i.v. BU in the conditioning regimen: Outcomes and risk factors for the occurrence of hepatic sinusoidal obstructive syndrome. Bone Marrow Transplant 49: 628-633.

4. Mohty M, Malard F, Abecassis M, Aerts E, Alaskar AS, et al. (2015) Sinusoidal obstruction syndrome/veno-occlusive disease: current situation and perspectives -apposition statement from the European Society for Blood and Marrow Transplantation (EBMT). Bone Marrow Transplant 50: 781-789.

5. Imran H, TleyjehI M, Zirakzadeh A, Rodriguez V, Khan SP (2006) Use of prophylactic anticoagulation and the risk of hepatic veno-occlusive disease in patients undergoing hematopoietic stem cell transplantation: A systematic review and meta-analysis. Bone Marrow Transplant 37: 677-686.

6. Cheuk DK, Chiang AK, Ha SY, Chan GC (2015) Interventions fo rprophylaxis of hepatic veno-occlusive disease in people undergoing haematopoietic stem cell transplantation. Cochrane Database Syst Rev 27: CD009311.

7. Gooley TA, Chien JW, Pergam SA, Hingorani S, Sorror ML, et al. (2010) Reduced mortality after allogeneic hematopoietic cell transplantation. N Engl J Med 363: 2091-2101.

8. Barker CC, Butzner JD, Anderson RA, Brant R, Sauve RS. (2003) Incidence, survival and risk factors for the development of veno-occlusive disease in pediatric hematopoeitc stem cell transplant recipients. Bone Marrow Transplant 32: 79-87.

9. Sun J, Huang SH, Tan BK, Whiteman M, Zhu YC, et al. (2005) Effects of purified herbal extract of Salviamiltiorrhizaon is chemicrat myocardium after acute myocardial infarction. Life Sci 76: 2849-2860.

10. Chen X, Guo J, Bao J, Lu J, Wang Y (2014) The anticancer properties of Salvia miltiorrhiza Bunge (Danshen): A systematic review. Med Res Rev 34: 768-794.

11. Maione F, DeFeo V, Caiazzo E, DeMartino L, Cicala C, et al. (2014) Tanshinon IIA, a major component of Salviamilthorriza Bunge, inhibits platelet activation via Erk-2 signaling pathway. J Ethnopharmacol 155: 1236-1242.

12. Jia JY, Lu YL, Li XC, Liu GY, Li SJ, et al. (2010) Pharmacokinetics of depside salts from Salvia miltiorrhiza in healthy Chinese volunteers: Arandomized, open-label, single-dose study. Curr Ther Res 71: 260-271.

13. Zeng Y, Song JX, Shen XC (2012) Herbal remedies supply a novel prospect for the treatment of atherosclerosis: A review of current mechanism studies. Phytother Res 26: 159-167.

14. Sheng S, Wang J, Wang L, Liu H, Li P, et al. (2014) Network pharmacology analyses of the antithrombotic pharmacological mechanism of FufangXueshuantong Capsule with experimental support using disseminated intravascular coagulationrats. J Ethnopharmacol 154: 735-744.

15. Wu WY, Wang YP (2012) Pharmacological actions and therapeutic applications of Salvia miltiorrhiza depside salt and its active components. Acta Pharmacol Sin 33: 1119-1130.

16. Yuan Y, Wu Q, Shi JS, Chen XP (2015) Advance in studies on hepatoprotective effect of Salvia miltiorrhiza and its main components. Zhongguo Zhong Yao Za Zhi 40: 588-593.

17. Chang Y, Zhang W, Xie Y, Xu X, Sun R, et al. (2014) Postmarketing safety evaluation: Depside salt injection made from Danshen (Radix Salviae Miltiorrhizae). J Tradit Chin Med 34: 749-753.

18. Quan W, Yin Y, Xi M, Zhou D, Zhu Y, et al. (2013) Antioxidant properties ofmagnesium lithospermate B contribute to the cardioprotection against myocardialischemia/reperfusion injury in vivo and in vitro. J Tradit Chin Med 33: 85-91.

19. Shulman HM, Hinterberger W (1992) Hepaticveno-occlusive diseaseliver toxicity syndrome after bone marrow transplantation. Bone Marrow Transplant 10: 197-214.

20. Carreras E, Bertz H, Arcese W, Vernant JP, Tomas JF, et al. (1998) Incidence and outcome of hepatic veno-occlusive disease after blood or marrow transplantation: A prospective cohort study of the European Group for Blood and Marrow Transplantation. European Group for Blood and Marrow Transplantation Chronic Leukemia Working Party. Blood 92: 3599-3604.

21. Maximova N, Ferrara G, Minute M, Pizzol A, Kiren V, et al. (2014) Experience from asingle paediatric transplant centre with identification of some protective and risk factors concerning the development of hepatic veno-occlusive disease in children after allogeneic hematopoietic stem cell transplant. Int J Hematol 99: 766-772. 